\title{
Volatile Organic Compound Concentrations and Emission Rates Measured over One Year in a New Manufactured House
}

\author{
Alfred T. Hodgson ${ }^{1 *}$, Steven J. Nabinger ${ }^{2}$ and Andrew K. Persily ${ }^{2}$ \\ ${ }^{1}$ Indoor Environment Department, Environmental Energy Technologies Division, Lawrence \\ Berkeley National Laboratory, Berkeley, CA 94720, USA \\ ${ }^{2}$ National Institute of Standards and Technology, Gaithersburg, MD 20899, USA
}

September 2004

\begin{abstract}
A study to measure indoor concentrations and emission rates of volatile organic compounds (VOCs), including formaldehyde, was conducted in a new, unoccupied manufactured house installed at the National Institute of Standards and Technology (NIST) campus. The house was instrumented to continuously monitor indoor temperature and relative humidity, heating and air conditioning system operation, and outdoor weather. It also was equipped with an automated tracer gas injection and detection system to estimate air change rates every $2 \mathrm{~h}$. Another automated system measured indoor concentrations of total VOCs with a flame ionization detector every $30 \mathrm{~min}$. Active samples for the analysis of VOCs and aldehydes were collected indoors and outdoors on 12 occasions from August 2002 through September 2003. Individual VOCs were quantified by thermal desorption to a gas chromatograph with a mass spectrometer detector (GC/MS). Formaldehyde and acetaldehyde were quantified by high performance liquid chromatography (HPLC).
\end{abstract}

Weather conditions changed substantially across the twelve active sampling periods. Outdoor temperatures ranged from $7{ }^{\circ} \mathrm{C}$ to $36^{\circ} \mathrm{C}$. House air change rates ranged from $0.26 \mathrm{~h}^{-1}$ to $0.60 \mathrm{~h}^{-1}$. Indoor temperature was relatively constant at $20^{\circ} \mathrm{C}$ to $24^{\circ} \mathrm{C}$ for all but one sampling event. Indoor relative humidity (RH) ranged from $21 \%$ to $70 \%$.

\footnotetext{
*Tel.: +1-510-486-5301. E-Mail: ATHodgson@lbl.gov
} 
The predominant and persistent indoor VOCs included aldehydes (e.g., formaldehyde, acetaldehyde, pentanal, hexanal and nonanal) and terpene hydrocarbons (e.g., a-pinene, 3-carene and d-limonene), which are characteristic of wood product emissions. Other compounds of interest included phenol, naphthalene, and other aromatic hydrocarbons. VOC concentrations were generally typical of results reported for other new houses. Measurements of total VOCs were used to evaluate short-term changes in indoor VOC concentrations.

Most of the VOCs probably derived from indoor sources. However, the wall cavity was an apparent source of acetaldehyde, toluene and xylenes and the belly space was a source of 2-butanone, lower volatility aldehydes and aromatic hydrocarbons. Indoor minus outdoor VOC concentrations varied with time. Adjusted formaldehyde concentrations exhibited the most temporal variability with concentrations ranging from $25 \mu \mathrm{g} \mathrm{m}^{-3}$ to $128 \mu \mathrm{g} \mathrm{m}^{-3}$ and the lowest concentrations occurring in winter months when indoor RH was low. A model describing the emissions of formaldehyde from urea-formaldehyde wood products as a function of temperature, $\mathrm{RH}$ and concentration reasonably predicted the temporal variation of formaldehyde emissions in the house. Whole-house emissions of other VOCs generally declined over the first three months and then remained relatively constant over a several month period. However, their emissions were generally lowest during the winter months. Also, an apparent association between TVOC emissions and outdoor temperature was observed on a one-week time scale.

Keywords: Manufactured house, air change rate, weather, volatile organic compound (VOC), formaldehyde, emission rate, indoor air quality

\section{Introduction}

Indoor exposures to toxic and irritating volatile organic compounds (VOCs) are of general concern. Residences are particularly important exposure environments for these compounds because people in the U.S.A. spend an average of $69 \%$ of their time indoors at home (Klepeis et al., 2001). In addition, residential ventilation rates, which serve as the primary mechanism for removal of gaseous pollutants generated indoors, are relatively low. The median air change rate measured in the 1980s for a large number of houses in the United States was $0.5 \mathrm{~h}^{-1}$ with houses in colder climates and in colder months having lower rates (Pandian et al., 1998). The recent trend in new construction is to make house envelopes tighter. Consequently, air change rates in 
houses being constructed without supplemental ventilation likely are low relative to historical values with a related potential for degraded indoor air quality.

In new unoccupied houses, the concentrations of formaldehyde and other VOCs of concern with respect to human health and comfort can be elevated relative to toxicity guidelines and odor thresholds (Hodgson et al., 2000). These gaseous pollutants derive from materials that are widely used to construct and to finish the interiors of houses (Hodgson et al., 2002). Efforts to improve indoor air quality in new houses likely can benefit from further investigation of the sources of VOC contamination and of the dynamic behavior of individual compounds of concern over both relatively short and long time periods.

A few studies have provided information on longitudinal trends in VOC concentrations and emissions in new houses (Lindstrom et al., 1995, Hodgson et al., 2002). In four manufactured houses, the area specific emission rates of formaldehyde and hexanal were generally similar at the beginning and end of the 7.5-month study period demonstrating that the sources of these compounds were not depleted rapidly (Hodgson et al., 2000).

In existing, occupied residential units, seasonal trends in VOC concentrations have been observed in a cross-sectional study in three German cities and in a longitudinal study of ten apartments (Schlink et al., 2004). This seasonal variation, with generally lower concentrations in summer months, might be due primarily to seasonally varying air change rates. Occupant behavior is a likely determinant of house ventilation since the opening of windows and doors has a dominant effect on house air change rate (Howard-Reed, et al., 2002). Concentrations of VOCs generated indoors may be presumed to decrease proportionally in response to increases in house ventilation. This has been documented in a new, unoccupied house for those VOCs with the highest vapor pressures (Hodgson et al., 2000). However, within chemical classes, the effectiveness of ventilation for reducing concentrations generally decreases with decreasing volatility (ibid.). The reduced effectiveness of ventilation for controlling the concentrations of less volatile compounds likely is due to sink effects in which the sorption of VOCs on interior surfaces and their diffusion into some materials is reversed when bulk air concentrations start to decline. Thus, ventilation alone may not be adequate to control the concentrations of less volatile VOCs generated by indoor sources such as building materials. 
In addition to ventilation, indoor temperature and humidity conditions, which can change both diurnally and seasonally, have the potential to substantially affect the emissions of VOCs from building materials and alter occupant exposure. In large-scale chamber experiments with new carpet systems, sheet vinyl flooring and wall paint, the air temperature was increased from $23{ }^{\circ} \mathrm{C}$ to about $30{ }^{\circ} \mathrm{C}$ over a period of $60 \mathrm{~h}$ (Hodgson, 1999). Concentrations and emissions of the target VOCs quickly increased in response to heating; upon termination of heating, they quickly returned to levels measured in control experiments without additional heating (ibid.). Thus, temperature is an important factor with direct and immediate effects. The influence of indoor temperature and relative humidity on the emissions and concentrations of formaldehyde has been studied and modeled in chamber experiments and research houses (Matthews et al., 1986; Silberstein, 1988). Modeling data for the research houses indicated that changing the indoor conditions from $20{ }^{\circ} \mathrm{C}, 30 \%$ relative humidity (RH) to $26^{\circ} \mathrm{C}, 60 \% \mathrm{RH}$ would result in two- to fourfold increases in formaldehyde concentration for the same air change rate (Matthews et al., 1986).

The current study was undertaken in a new manufactured house set up as a research facility. The plan was to conduct longitudinal measurements of VOC concentrations in the house along with measurements of key physical parameters including house air change rate, indoor and outdoor temperature and relative humidity, and wind conditions over a period of approximately one year. The primary objective was to evaluate changes in the emissions of formaldehyde and other VOCs in response to time, house air change rate, and the other parameters. In addition, measurements were conducted to examine the potential influence of unconditioned spaces on VOC concentrations in the conditioned living area.

\section{Methods}

\section{Description of Study House}

The study building is a doublewide manufactured house built to U.S. Department of Housing and Urban Development (HUD) Manufactured Home Construction and Safety Standards (HUD, 1994). The house was manufactured in Pennsylvania and was installed in February 2002 on the National Institute of Standards and Technology (NIST) campus in Gaithersburg, MD for use as a ventilation and indoor air quality research facility. It is generally typical of mid-range manufactured houses in the eastern USA with respect to size, interior finish materials, heating 
and air conditioning equipment, and price. The photograph in Figure 1 shows the front elevation of the house. The floor plan is depicted in Figure 2, and a schematic side elevation is shown in Figure 3.

The house is $17.0 \mathrm{~m}$ long and $8.2 \mathrm{~m}$ wide, with a height of $3.4 \mathrm{~m}$ from the ground to the crest of the roof. The floor area is $127 \mathrm{~m}^{2}$; the enclosed volume is $310 \mathrm{~m}^{3}$. The floor plan consists of three bedrooms, two bathrooms and a combined family, kitchen, dining and living area. The subfloor is plywood; $17 \%$ of the floor area is resilient vinyl flooring; $72 \%$ of the floor area is carpeted. The house is unfurnished with the exception of preinstalled kitchen and bath cabinetry and the monitoring equipment (described below) used in this study.

The house has a cement block, crawl space foundation. The vented volume of the crawl space is about $115 \mathrm{~m}^{3}$. The under-floor belly volume defined by the floor joists and the metal frame is approximately $65 \mathrm{~m}^{3}$. The belly space contains the heating and cooling (HAC) supply air distribution ductwork, plumbing lines and thermal insulation and is separated from the crawl space by an insulated, woven polyethylene membrane. The attic space has a volume of $43 \mathrm{~m}^{3}$ above the vaulted ceiling. There are five roof vents and a series of eave vents extending along the perimeter of the house.

The forced air HAC system is located off the dining area with a single return grille located in a panel of the HAC system closet. The HAC system consists of a $10.6 \mathrm{~kW}$ air conditioning unit and a furnace with a power input of $22.6 \mathrm{~kW}$ and output of $18.2 \mathrm{~kW}$. The design airflow rate of the furnace fan is $470 \mathrm{~L} \mathrm{~s}^{-1}$. A thermostat controls system operation, but the air distribution fan can be operated continuously if desired. There are local exhaust fans in the bathrooms and kitchen and a whole-house exhaust fan in the ceiling near the HAC closet. There is an outdoor air intake duct connected to the return side of the forced air system, which supplies outdoor air whenever the system operates. However, the outdoor air intake was sealed during the measurements described here.

The house has 11 dual-pane double hung windows in the north, south and west exterior walls. There are no windows on the east wall. Each window has a passive air vent at the top to supply outdoor air to the house, but these vents were closed during the measurements.

The air tightness of the house was determined by fan pressurization tests conducted according to ASTM E 779 (ASTM, 2003). These tests yielded an air change rate of $11.8 \mathrm{~h}^{-1}$ at 
50 Pa pressure differential and an effective leakage area of $728 \mathrm{~cm}^{2}$ at $4 \mathrm{~Pa}$ pressure differential (Persily et al., 2003). These results are generally typical of other recently constructed U.S. manufactured houses (Persily and Martin, 2000). More information on the measurements of exterior envelope leakage, duct air tightness, HAC system airflow rates, and whole house air change rates under different $\mathrm{HAC}$ configurations and weather conditions were reported previously (Persily et al., 2003).

\section{Instrumentation and Analyses}

An automated data acquisition system was installed to monitor the indoor air temperatures and humidities, HAC operation, building pressures, and outdoor weather. An automated tracer-gas system for continuous monitoring of house air change rates also was installed. This system injected sulfur hexafluoride $\left(\mathrm{SF}_{6}\right)$ into the house every $4 \mathrm{~h}$ to $6 \mathrm{~h}$, allowed it to mix to a uniform concentration, and then monitored the concentration decay in several zones. Air change rates were calculated as the slope of the least squares linear regression of the natural log of the $\mathrm{SF}_{6}$ concentration in the living space.

Active sampling for VOCs and aldehydes was conducted on 12 dates between August 8, 2002 and September 25, 2003. For each sampling event, the house was operated for at least $48 \mathrm{~h}$ prior to sampling and during sampling at a standardized condition. In this condition, all exterior windows and doors were closed, all interior doors were open, window vents were closed, the HAC fan was operated continuously with the outdoor air intake sealed, and the indoor temperature was maintained by thermostatic control of the heating or air conditioning equipment. Air samples for VOCs and aldehydes were in the central living area (i.e., living room), the adjacent master bedroom, and outdoors. The indoor air samples were positioned about $1.5 \mathrm{~m}$ above the floor. Additional samples were collected from other locations outside of the conditioned space (i.e., interior cavity of south wall, belly space and crawl space) during nine of the 12 events.

Air samples for VOCs were collected on sorbent tubes (P/N CP-16251, Varian Inc.) modified by substituting a 15 -mm section of 60/80-mesh carbon molecular sieve (P/N 10184, Supleco Inc.) at the outlet end. Air was pulled through the sorbent tubes using dual-headed adjustable flow pumps with electronic flow calibrators at the exits to continuously monitor sample flow rates between $20 \mathrm{~mL} \mathrm{~min}^{-1}$ and $300 \mathrm{~mL} \mathrm{~min}^{-1}$ with an accuracy of $\pm 2 \%$ of the 
measured value. Pump flow rates for VOCs, measured during each sampling period, were about $75 \mathrm{~mL} \mathrm{~min}^{-1}$ collected over $10 \mathrm{~min}$ to $20 \mathrm{~min}$ yielding sample volumes of about $0.75 \mathrm{~L}$ to $1.5 \mathrm{~L}$. Each sample was collected in duplicate. Field blanks also were included during each sampling period.

VOC samples were quantitatively analyzed for individual compounds by thermal desorption-gas chromatography/mass spectrometry (GC/MS) (U.S. EPA, 1984). Samples were thermally desorbed and concentrated on a cryogenic inlet system (Model CP-4020 TCT, Varian, Inc.) fitted with a packed trap (P/N CP-16425, Varian, Inc.). The sample desorption temperature was $235{ }^{\circ} \mathrm{C}$ for $6.5 \mathrm{~min}$. The cryogenic trap was held at $-100{ }^{\circ} \mathrm{C}$, and then heated to $235^{\circ} \mathrm{C}$ for injection. The analytical column was 0.25 -mm ID, 30-m long with a $1 \mu \mathrm{m}$-film $(14 \%$ cyanopropyl-phenyl)-methylpolysiloxane bonded phase (P/N 122-0733, Agilent Technologies). The GC oven was ramped from $1{ }^{\circ} \mathrm{C}$ to $225^{\circ} \mathrm{C}$. The MS was operated in electron impact mode and scanned from $\mathrm{m} / \mathrm{z} 30$ to 350. Multi-point calibrations were created and referenced to an internal standard of 1-bromo-4-fluorobenzene. There were approximately 50 target compounds spanning broad ranges of volatility and chemical functionality. The volatility range was approximately bounded by n-pentane and n-heptadecane.

Air samples for formaldehyde and acetaldehyde were collected on treated silica-gel cartridges (P/N WAT047205, Waters Corp.) using separate pumps. Sampling flow rates were $2.0 \mathrm{~L} \mathrm{~min}^{-1}$ collected over $15 \mathrm{~min}$ to 30 min yielding sample volumes of about $30 \mathrm{~L}$ to $60 \mathrm{~L}$. Each cartridge was extracted with $2 \mathrm{~mL}$ of acetonitrile. Extracts were analyzed by highperformance liquid chromatography with a diode array detector at a wavelength of $365 \mathrm{~nm}$ following ASTM D 5197 (ASTM, 1997a). Extract concentrations were determined from multipoint calibrations of external standard mixtures.

Semi real time measurements of total VOC (TVOC) concentrations were made at 30-min intervals using a transportable GC (Model 8610C, SRI Instruments) installed inside the house. The GC was equipped with dual independent sampling and analysis systems for detecting and quantifying TVOC from two locations simultaneously. The two systems were identical. Both consisted of a sample inlet leading to a sorbent bed for concentrating VOCs, a multiposition valve and associated plumbing. The sorbent beds were packed with a graphite impregnated porous polymer. The analytical columns were 15-m, 0.53-mm ID with a non-polar 
bonded phase. Analyses were performed with flame ionization detectors (FIDs). Sampling pumps and manual valves were connected upstream of the sorbent beds. Air was pulled through 3-mm OD polytetrafluoroethylene (PTFE) tubing, from selected locations. The tubing length ranged from $2 \mathrm{~m}$ to $9 \mathrm{~m}$ for the outdoor sampling location, which was farthest from the GC. Sampling flow rates were measured weekly, and the valves were adjusted as required to maintain constant rates. The sampling and analytical process was computer controlled.

TVOC was determined as the sum of all chromatographic peaks in a sample bounded by approximately n-octane and $\mathrm{n}$-tetradecane. A toluene-equivalent sample mass was calculated using a five-point toluene calibration performed monthly. Single point calibration checks were performed biweekly.

TVOC was measured nearly continuously over the course of the study. During the several-day intervals associated with active sampling for VOCs, samples from two locations were variously drawn from the main living area, master bedroom, interior cavity of the south wall, belly space and crawl space.

\section{Data Analysis}

Standard deviations (i.e., precision) for the analyses of VOCs by GC/MS were calculated by analysis of variance from the sample-pair data. Ten sets of duplicate indoor samples were used in the analysis. Relative precision expressed in percent was calculated by dividing the standard deviation by the median concentration for the 20 samples.

Emission rates (ERs) of the target compounds in mass per time $\left(\mu \mathrm{g} \mathrm{h}^{-1}\right)$ were derived assuming the house was an ideal continuously-stirred tank reactor (CSTR) operating at near steady-state conditions (ASTM, 1997b). Net losses of compounds due to factors other than ventilation, e.g., sink effects, were ignored. The steady-state form of the mass-balance model for a CSTR was used:

$$
E R=V a\left(C-C_{0}\right)
$$

where $\mathrm{V}$ is the ventilated volume of the house $\left(\mathrm{m}^{3}\right)$; a is the air change rate $\left(\mathrm{h}^{-1}\right)$; $\mathrm{C}$ is the air concentration of the compound in the house $\left(\mu \mathrm{g} \mathrm{m}^{-3}\right)$; and $\mathrm{C}_{0}$ is the outdoor air concentration $(\mu \mathrm{g}$

$\left.\mathrm{m}^{-3}\right)$. Area-specific emission rates or emission factors (EFs) in mass per area-time $\left(\mu \mathrm{g} \mathrm{m}^{-2} \mathrm{~h}^{-1}\right)$ were calculated by dividing the corresponding emission rates by the floor area $\left(\mathrm{m}^{2}\right)$ of the house. 


\section{Results}

Table 1 presents indoor and outdoor temperatures and relative humidities, wind conditions and house air change rates during the approximate two-hour periods of active VOC sample collection on 12 dates. With the exception of the April 17, 2003 sampling event, indoor temperature during sampling was maintained within a $20{ }^{\circ} \mathrm{C}$ to $24{ }^{\circ} \mathrm{C}$ range by thermostat operation of the HAC system. Outdoor temperature varied between $7{ }^{\circ} \mathrm{C}$ and $36{ }^{\circ} \mathrm{C}$ on the sampling dates. Indoor relative humidity $(\mathrm{RH})$ varied over a relatively broad range of $21 \%$ to $70 \%$ with the lowest $\mathrm{RH}$ $(\leq 25 \%)$ occurring on the December through April sampling dates. House air change rates during sampling ranged from $0.26 \mathrm{~h}^{-1}$ to $0.60 \mathrm{~h}^{-1}$.

A broad range of VOCs were identified and individually quantified. Twenty-two of these were selected as target compounds (Table 2). These targets either were the predominant and persistent compounds or are of interest due to their potential effects on occupant comfort and health. Numerous isomers of $\mathrm{C}_{3}$ to $\mathrm{C}_{4}$ alkyl substituted benzenes were present, but not quantified. Acetic acid, an apparently abundant VOC, also was not quantified. The target VOCs are listed in the tables by chemical class (i.e., alcohols, ketones, aldehydes, aromatic hydrocarbons, terpene hydrocarbons and alkane hydrocarbons) and by decreasing volatility within class. Many of the VOCs were measured with good precision (i.e., $\leq 15 \%$ ) as determined from the analysis of ten sets of duplicate indoor samples (Table 2). The exceptions were 2-butanone, heptanal, nonanal, toluene and combined $\mathrm{m} / \mathrm{p}$-xylene isomers. Indoor concentrations first were adjusted by subtracting the corresponding outdoor concentrations, and then the living room and master bedroom concentrations were averaged. These average, adjusted, indoor concentrations determined over the 10 or 12 sampling events are summarized in Table 2 as medians and ranges. The most abundant target VOCs (defined here as median concentrations $\geq 25 \mu \mathrm{g} \mathrm{m}^{-3}$ ) were formaldehyde, hexanal, $\alpha$-pinene, $\mathrm{n}$-tridecane and $\mathrm{n}$ tetradecane.

There was good agreement between adjusted (i.e., indoor minus outdoor) VOC concentrations measured in the living room and master bedroom. For individual VOCs, the average fractional difference determined as the living room minus the bedroom concentration divided by the average concentration was positive, $<0.1$, and statistically non-significant (2-tailed Student's t test, $\mathrm{p}>0.95$ ) with several exceptions (Table 3 ). The concentrations of four VOCs 
often associated with motor vehicle exhaust emissions (toluene, styrene, $\mathrm{m} / \mathrm{p}$-xylene and 1,2,4-trimethylbenzene) were significantly higher in the living room. Phenol concentrations also were significantly higher in the living room. $\alpha$-Terpinol, formaldehyde, and acetaldehyde concentrations were lower on average in the living room, but the differences were not significant.

Wall cavity VOC concentrations were measured during three sampling events. For the majority of compounds, the average fractional difference between the adjusted wall and the average adjusted indoor concentration was negative and within the range of -0.2 to -0.6 (Table 3). The notable exceptions were acetaldehyde, toluene and $\mathrm{m} / \mathrm{p}$-xylene, which had wall cavity concentrations 2 to 6 times higher than their corresponding indoor concentrations.

VOC concentrations in the belly space were measured during four sampling events. Adjusted belly concentrations were compared to average adjusted indoor concentrations (Table 3). Here the fractional differences were positive for all compounds. For a number of VOCs, these differences were substantial (2-butanone, less volatile aldehydes, alkane hyrdrocarbons, and aromatic hydrocarbons except styrene). Although not quantified, the $\mathrm{C}_{3}$ to $\mathrm{C}_{4}$ alkyl substituted benzene isomers also were, from visual inspection of the total-ion-current chromatograms, elevated in the belly space relative to indoors. Note that the belly space is a complex space with some compartmentalization from structural members and substantial supply duct leakage (approximately $125 \mathrm{~L} \mathrm{~s}^{-1}$ ) at unknown locations (Persily et al., 2003). Therefore, results obtained for the single sampling location in the belly may not be representative of average VOC concentrations over the entire belly space.

Crawl space concentrations were measured during five sampling events. Adjusted crawl space concentrations were compared to average adjusted indoor concentrations (Table 3). With two exceptions, the fractional differences were negative and within the range of -0.3 to -0.8 due to lower concentrations in the crawl space relative to indoors. The exceptions were 2-butanone and $\mathrm{m} / \mathrm{p}$-xylene with slightly elevated concentrations in the crawl space.

Changes in adjusted mean indoor minus outdoor concentrations of 12 of the 22 VOCs over the course of the study are presented in Figures 4 and 5. These plots show that the concentrations of the predominant, persistent VOCs ranged over factors of approximately 3 to 7 among the 10 or 12 sampling events. This variation is greater than the approximate two-fold variation in the air change rate (i.e., $0.26 \mathrm{~h}^{-1}$ to $0.60 \mathrm{~h}^{-1}$ ) (Table 1). 
Emission factors $\left(\mu \mathrm{g} \mathrm{m}^{-2} \mathrm{~h}^{-1}\right)$ were calculated for the 22 target VOCs in each sampling event. The average emission factors determined over the 10 or 12 sampling events are summarized in Table 2 as medians and ranges. The median values for eight of the compounds were $<5 \mu \mathrm{g} \mathrm{m}^{-2} \mathrm{~h}^{-1}$ and were, thus, quite low. Temporal changes in the emission factors of 11 of the most abundant VOCs are presented in Figures 6 and 7. Many of these compounds displayed a similar pattern, often with the highest emission factors occurring in the first one to two months, generally low values occurring in months with outdoor temperatures below indoor temperatures, and elevated values occurring on April 17, 2003 when the average indoor temperature was $28{ }^{\circ} \mathrm{C}$. Formaldehyde was a notable exception. The formaldehyde emission factors were highest and approximately the same at the beginning and end of the study during periods of warmer weather and higher indoor RH.

The emission factors of the 14 most abundant VOCs on sequential cold weather sampling dates (January 17 and March 12, 2003) are compared in Table 4. Indoor and outdoor temperatures and percent RHs were approximately equivalent between these dates (Table 1). However, the January air change rate was $0.58 \mathrm{~h}^{-1}$ versus $0.31 \mathrm{~h}^{-1}$ in March, likely due to the difference in wind conditions. Within both the aldehyde and the terpene hydrocarbon chemical classes, the ratio of the emission factor at the lower air change rate to the emission factor at the higher air change rate was near unity for the most volatile compounds and generally decreased with decreasing compound volatility. Thus, the emission rates of the less volatile VOCs increased with increasing air change rate compared to the low air change rate condition. Acetaldehyde was an exception to this pattern.

Semi real time measurements of TVOC concentration were acquired with the GC/FID instrument for most weeks of the study. One week of hourly TVOC data in the cooling season during which day-to-day variations were similar was selected for preliminary analysis (more detailed analysis of these data is planned). TVOC concentrations for the one-week period of June 9 - 16, 2003 (active samples were collected three days prior) are plotted in Figure 8 along with the corresponding house air change rates calculated as averages for measurements made at three indoor locations. The median TVOC concentration for the period was $308 \mu \mathrm{g} \mathrm{m}^{-3}$. The median air change rate was $0.40 \mathrm{~h}^{-1}$; most values ranged between $0.3 \mathrm{~h}^{-1}$ and $0.5 \mathrm{~h}^{-1}$. Indoor and outdoor temperatures calculated as 30-min averages are shown in Figure 9 for the same period. 
Outdoor temperatures varied diurnally with mid to late afternoon temperatures on five of seven days reaching at least $30{ }^{\circ} \mathrm{C}$. Over night temperatures on these same days were typically about $20{ }^{\circ} \mathrm{C}$. Indoor temperatures were relatively constant at about $21{ }^{\circ} \mathrm{C}$.

\section{Discussion}

The composition of VOCs in the study house was typical of new North American manufactured and site-built houses. The most abundant VOCs measured in new houses have included formaldehyde, acetaldehyde, less volatile aliphatic aldehydes (e.g., pentanal, hexanal, nonanal), 2-butanone, terpene hydrocarbons (e.g., $\alpha$-pinene, 3-carene, d-limonene), and alkane and aromatic hydrocarbons (Lindstrom et al., 1995; Hodgson et al., 2000 and 2002). The concentrations of the most abundant VOCs also were generally similar to their respective concentrations reported for other new manufactured houses (Hodgson et al., 2000 and 2003). The median formaldehyde concentration of $84 \mu \mathrm{g} \mathrm{m}^{-3}$ was near the upper limit of reported values; while the median hexanal concentration of $45 \mu \mathrm{g} \mathrm{m}^{-3}$ was near the lower limit. The sources of formaldehyde, acetaldehyde, other aliphatic aldehydes and terpene hydrocarbons are predominantly wood-derived products used to finish the interiors of houses (Baumann et al., 1999; Kelly et al., 1999; Hodgson et al., 2002). These products include cabinetry components such as the exposed undersides of particleboard or medium density fiberboard (MDF) counter tops and exposed particleboard or MDF casework surfaces, fiberboard passage doors, and plywood sub flooring under carpeted areas (Hodgson et al., 2002).

The generally good agreement between the living room and the master bedroom concentrations indicates that the air within these primary living spaces was well mixed at the sampling condition. This result was consistent with the uniform tracer gas concentrations observed in the house, but may also be an indication of fairly uniform emission rates throughout the building. One exception is the polyvinyl chloride (PVC) resilient flooring, which covered a higher fraction of the floor area in the main living area. Some PVC flooring products are a source of phenol (Hodgson, 1999; Cox et al., 2001). Thus, this flooring may have contributed to the small, but significantly higher concentration in the main living room versus the master bedroom. The possible source of the significantly higher concentrations of aromatic hydrocarbons in the living room is unknown. 
The extent to which external spaces contributed to VOC concentrations in the living spaces could not be determined readily from the results. However, both the wall cavity and the belly spaces apparently contained sources of compounds that also were present indoors. The elevated concentrations of toluene, $\mathrm{m} / \mathrm{p}$-xylene and acetaldehyde in the wall cavity versus indoors suggest a source(s) of these compounds located within the wall. The belly space contained sources of 2-butanone, lower volatility aldehydes (pentanal through nonanal), aromatic hydrocarbons except styrene and alkane hydrocarbons (n-tridecane and n-tetradecane). The aldehydes likely were emitted by wood-derived products. A possible source is the plywood subfloor. However, terpene hydrocarbons, which are also associated with plywood (Hodgson et al., 2002), were not elevated in the belly. Construction adhesives can be a source of aromatic hydrocarbons (Hodgson, 2003) and possibly alkane hydrocarbons. The VOC composition of crawl space air was similar to the composition of indoor air, but the concentrations were almost universally lower. This may have been the result of higher air change rates in the crawl space, due in part to duct leakage flowing through the crawl space.

Temporal variations in indoor VOC concentrations in the house likely were affected by changes in the sources with age and in the house parameters, principally air change rate, temperature and relative humidity. Air change rates in the house, which was operated at a single defined condition for all the sampling periods, were affected by wind speed and temperature conditions. At low wind speed conditions (wind speed $<2 \mathrm{~m} \mathrm{~s}^{-1}$ ) with the forced-air system either on or off, the air change rate is predicted by the indoor minus outdoor temperature differential $(\Delta \mathrm{T})$ (Persily et al., 2003). The house air change rates induced by wind conditions and $\Delta \mathrm{T}$ during the 12 sampling events ranged over a factor of 2.3. However, adjusted indoor VOC concentrations varied over a wider range, up to a factor of approximately six to seven for some abundant compounds, suggesting the importance of other factors.

Changes in the concentrations of the most volatile VOCs are presumably related directly to changes in ventilation if their source emissions remain constant. This was observed for formaldehyde, pentanal, hexanal, and $\alpha$-pinene (i.e., emission factors within $\pm 10 \%$ ) at the January and March, 2003 sampling events in which the air change rate varied by approximately a factor of two while the indoor and outdoor environmental conditions were nearly equivalent. For the less volatile compounds, the emission rates increased as the ventilation rate increased. A 
similar result showing an increase in emission rates for lower volatility compounds with increasing ventilation rate was presented previously for another new house (Hodgson et al., 2000) and has been observed in an office building (Hodgson et al., 2003). This result indicates the potential importance of sink effects in determining temporal pattern of concentrations and emission rates for less volatile VOCs. The sorption of VOCs on interior surfaces and their diffusion into some materials is followed by later release when bulk air concentrations decline. For some common VOC source profiles and VOC/material combinations, the effect is predicted to be relatively large (Zhao et al., 2002). Experiments with gas-phase constituents of environmental tobacco smoke in a simulated room environment have directly demonstrated that exposures to the less volatile VOCs can persist long after smoking has occurred due to reemission (Singer et al., 2003). This phenomenon directly links emissions of some VOCs with ventilation and can partially negate the benefit of increased ventilation as a control mechanism for VOC exposures.

There was an apparent relationship between the emissions of TVOC and outdoor temperature or the difference between indoor and outdoor temperatures. TVOC emission factors are plotted versus the outdoor temperature in Figure 10 for the same period of time discussed in reference to Figures 8 and 9. The relationship of TVOC emission factors and the temperature differential (not shown) is nearly identical. There was a general trend of increased TVOC emission factors at higher outdoor temperatures (regression coefficient, $\mathrm{r}^{2}=0.43$ ). Without speciated data, the underlying cause for this trend is difficult to diagnose. Higher outdoor temperatures are associated with increased ventilation rate as shown by Persily et al. (2003). In their analysis of the ventilation characteristics of the house, air change rates at low wind speed conditions with the HAC operating are predicted to vary by about $0.15 \mathrm{~h}^{-1}$ over the approximate $7.5^{\circ} \mathrm{C}$ to $-12.5^{\circ} \mathrm{C}$ differential observed during the selected week. As noted above, the apparent emission factors of less volatile compounds are expected to increase at higher ventilation rates due to their re-emission from surfaces. Higher outdoor temperatures also are associated with increased operating time for the air conditioning system, which is a possible source of VOC contamination either from materials within the system or from duct leakage in the belly space returning to the living space through leaks in the floor. Higher outdoor temperatures additionally may increase VOC emissions in unconditioned portions of the building envelope such as the attic space, wall cavities, and belly space. 
For a number of the target VOCs, emission factors were highest in the first months of the study relative to the final month at similar weather conditions. This likely was due to a slow depletion of the sources with time following production and installation of the house. The generally elevated emission factors on April 17, 2003 relative to the immediately proceeding and subsequent sampling events likely can be attributed to the elevated indoor temperature $\left(28{ }^{\circ} \mathrm{C}\right)$ on this date. The generally low emission factors on the dates between November 2002 and March 2003 were coincident with low outdoor temperatures and low indoor RH. Air change rates also were relatively low during this period with the exception of the January 2003 date. As noted above, the less volatile VOCs would be expected to have lower emission factors at low air change rates due to sorption and re-emission effects. However, some of the more volatile compounds (e.g., pentanal and hexanal) exhibited the largest emission factor variations. The mechanism by which outdoor temperatures affect VOC emissions from indoor sources held at relatively constant temperature is not clear. One possible explanation is that temperature dependent VOC emissions in unconditioned spaces (e.g. attic space, wall cavities and belly space) were impacting indoor air. Attic concentrations were not measured. However, several VOCs with elevated concentrations in the belly space (e.g., hexanal, naphthalene, n-tridecance) relative to indoors had lower emission factor variations than other VOCs not strongly associated with this space. This observed behavior might suggest that temperature fluctuations in the belly space were not a predominant factor.

The temporal profile of formaldehyde emission factors was somewhat unique. Matthews et al. (1986) developed an empirical model to describe the emission rate of formaldehyde from wood-derived products at any temperature, $\mathrm{RH}$ and ambient formaldehyde concentration. Silberstein et al. (1988) undertook experiments with particleboard, medium density fiberboard (MDF) and hardwood plywood paneling to validate the model in test chambers and a prototype house. Using the equations and parameters provided by Silberstein et al. (Equations 3-9, Table IV), normalization factors were calculated for the temperature, humidity and formaldehyde condition on each sampling date. The parameters for particleboard were selected as being most representative of the type of wood-derived product in the house. At $23{ }^{\circ} \mathrm{C}$ and $50 \% \mathrm{RH}$, the relationship between the measured and predicted emission factors with concentration $(\mathrm{C})$ in $\mu \mathrm{g}$ $\mathrm{m}^{-3}$ is $1.38-0.00308 \times \mathrm{C}$ assuming a $443 \mu \mathrm{g} \mathrm{m}^{-3}$ cutoff concentration above which emissions do not occur. Thus, at the standard conditions and $61.8 \mu \mathrm{g} \mathrm{m}^{-3}(50 \mathrm{ppb}(\mathrm{v}))$, the emission factor 
would be 1.19 times the emission factor at $124 \mu \mathrm{g} \mathrm{m}{ }^{-3}(100 \mathrm{ppb}(\mathrm{v}))$. At $23{ }^{\circ} \mathrm{C}, 25 \% \mathrm{RH}$ and 124 $\mu \mathrm{g} \mathrm{m}^{-3}$, the emission factor would be 0.41 times the emission factor at the standard conditions due to the large effect of humidity on formaldehyde release from the hydrolysis of ureaformaldehyde resin in wood products. We applied the calculated normalization factors to the derived emission factors for each sampling event setting the predicted emission factor equal to the derived emission factor on December 12, 2002. The comparison between the derived and predicted rates shown in Figure 11 demonstrates that the model provides a reasonable depiction of the depression of formaldehyde emission factors for the sampling events when the indoor RH was $40 \%$ and lower. This suggests that indoor humidity has a substantial impact on formaldehyde emission rates and concentrations.

\section{Conclusions}

Concentrations and emissions of VOCs in this new manufactured house were shown to vary over different time scales. The general decline in the emissions of many VOCs over time reasonably can be attributed to the gradual depletion of sources as the building materials aged. A distinct seasonal effect was observed for many VOCs. Generally, the lowest emissions occurred during the winter months with low outdoor temperatures and low indoor relative humidity. With the limited data available, it was not possible to determine the probable cause for most compounds. If outdoor temperature was producing a direct effect, it must have been due to the influence of temperature on emissions in unconditioned spaces in the building such as the attic, wall cavities, and belly space, which then were communicated by movement of air to the conditioned space. Indoor relative humidity was shown to be a likely cause of the changes in formaldehyde emission factors with season. This phenomenon is sufficiently understood so that an empirical model was able to predict with reasonable accuracy higher formaldehyde emission factors at higher indoor humidity. Indoor humidity levels probably do not directly affect the emissions of the other VOCs, but may play an indirect role, which is poorly understood at this time.

Short-term fluctuations in VOC concentrations and emissions also were observed. Air change rates in the house have been shown to respond to diurnal outdoor temperature swings. This study also demonstrated a diurnal change in TVOC emission factors with the lowest emission factors occurring at the lowest outdoor temperatures. For the least volatile compounds, this effect can at least partially be explained by the sorption (and diffusion) of VOCs on indoor 
surfaces. These compounds are later re-emitted to air as the air change rate increases. However, other poorly understood factors probably contributed to short-term changes in VOC emission factors. Possible contributing factors include emissions from components of the HAC system and substantial duct leakage into the belly space and possible reentry of air through openings in the floor.

Much remains to be discovered about the dynamics of VOC sources in even relatively simple buildings such as this small manufactured study house. A detailed investigation involving more extensive instrumentation, multi-zone tracer gas experiments and near real-time monitoring of individual VOCs in both conditioned and unconditioned spaces would probably help to resolve some of the unanswered questions. This information could perhaps be used to devise effective control strategies for VOCs of concern such as formaldehyde and other known toxicants. However, VOC source reduction is likely to remain the most effective means of lowering occupant exposures. For example, the data suggest that reduction of ureaformaldehyde, composite wood sources would likely lower formaldehyde exposures. The study also suggests that more attention should be given to reducing sources in unconditioned spaces and/or in reducing the flow rates of air between unconditioned and conditioned spaces.

\section{Acknowledgements}

The authors thank Tosh Hotchi and Diane Ivy of LBNL for assistance with VOC analyses and the VOC database. The work at LBNL was supported by the Assistant Secretary for Energy Efficiency and Renewable Energy, Building Technology Program of the U.S. Department of Energy (DOE) under contract No. DE-AC03-76SF00098.

\section{Disclaimer}

Certain trade names and company products are mentioned in the text in order to adequately specify the experimental procedures and equipment used. In no case does such identification imply recommendation or endorsement by the National Institute of Standards and Technology or Lawrence Berkeley National Laboratory, nor does it imply that the equipment are the best available for the purpose. 


\section{References}

ASTM. 1997a. Standard Test Method for Determination of Formaldehyde and Other Carbonyl Compounds in Air (Active Sampler Methodology). West Conshohocken, PA, ASTM International (ASTM Standard D 5197-97).

ASTM. 1997b. Standard Guide for Small-Scale Environmental Chamber Determinations of Organic Emissions from Indoor Materials/Products. West Conshohocken, PA, ASTM International (ASTM Standard D 5116-97).

ASTM. 2003. Standard Test Method for Determining Air Leakage Rate by Fan Pressurization. West Conshohocken, PA, ASTM International (ASTM Standard E 779-03)

Baumann MGD, Batterman SA and Zhang G-Z. 1999. Terpene emissions from particleboard and medium-density fiberboard products. Forest Products Journal 49: 49-56.

Cox SS, Hodgson AT and Little JC. 2001. Measuring concentrations of volatile organic compounds in vinyl flooring. Journal Air \& Waste Management Association 51: 174-185.

Hodgson AT. 1999. Common Indoor Sources of Volatile Organic Compounds: Emission Rates and Techniques for Reducing Consumer Exposures. Sacramento, CA, California Environmental Protection Agency, Air Resources Board, Research Division (Final Report, Contract No. 95-302).

Hodgson AT, Beal D and McIlvaine JER. 2002. Sources of formaldehyde, other aldehydes and terpenes in a new manufactured house. Indoor Air 12: 235-242.

Hodgson AT, Faulkner D, Sullivan DP, DiBartolomeo DL, Russell ML and Fisk WJ. 2003. Effect of outside air ventilation rate on volatile organic compound concentrations in a call center. Atmospheric Environment 37: 5517-5527.

Hodgson AT, Rudd AF, Beal D and Chandra S. 2000. Volatile organic compound concentrations and emission rates in new manufactured and site-built houses. Indoor Air 10: 178-192.

Howard-Reed C, Wallace LA and Ott WR. 2002. The effect of opening windows on air change rates in two homes. ISSN 1047-3289. Journal of Air \& Waste Management Association 52: 147-159.

HUD, 1994. Manufactured Home Construction and Safety Standards. Part 3280. Washington, DC: U.S. Department of Housing and Urban Development.

Kelly TJ, Smith DL and Satola J. 1999. Emission rates of formaldehyde from materials and consumer products found in California Homes. Environmental Science \& Technology 33: 8188 .

Lindstrom AB, Proffitt D and Fortune CR. 1995. Effects of modified residential construction on indoor air quality. Indoor Air 5: 258-269.

Matthews TG, Fung KW, Tromberg BJ and Hawthorne AR. 1986. Impact of indoor environmental parameters on formaldehyde concentrations in unoccupied research houses. JAPCA 36: 1244-1249. 
Pandian MD, Behar JV, Ott WR, Wallace LA, Wilson AL, Colome SD and Koontz M. 1998. Correcting errors in the nationwide data base of residential air change rates. Journal of Exposure Analysis and Environmental Epidemiology 8: 577-587.

Persily A, Crum J, Nabinger S and Lubliner M. 2003. Ventilation characterization of a new manufactured house. Proceedings of $24^{\text {th }}$ AIVC \& BETEC Conference, Ventilation, Humidity Control and Energy: 295-300.

Persily AK and Martin S. 2000. A modeling study of ventilation in manufactured houses. NISTIR 6455. Gaithersburg, MD: National Institute of Standards and Technology.

Schlink U, Rehwagen M, Damm M, Richter M, Borte M and Herbarth O. 2004. Seasonal cycle of indoor-VOCs: comparison of apartments and cities. Atmospheric Environment 38: 11811190.

Silberstein S, Grot RA, Ishiguro K and Mulligan J. 1988. Validation of models for predicting formaldehyde concentrations in residences due to pressed-wood products. JAPCA 38: 14031411.

Singer BC, Hodgson AT and Nazaroff WW. 2003. Gas-phase organics in environmental tobacco smoke: 2. Exposure-relevant emission factors and indirect exposures from habitual smoking. Atmospheric Environment 37: 5551-5561.

U.S. EPA. 1984. Method TO-1, Revision 1.0: Method For The Determination Of Volatile Organic Compounds in Ambient Air Using Tenax ${ }^{\circledR}$ Adsorption and Gas Chromatography/Mass Spectrometry (GC/MS), Center for Environmental Research Information, Office of Research and Development, United States Environmental Protection Agency.

Zhao D, Little JC and Hodgson AT. 2002. Modeling the reversible, diffusive sink effect in response to transient contaminant sources. Indoor Air 12: 184-190. 
Table 1. Indoor and outdoor temperature and relative humidity, wind conditions and house air change rate $(\mathrm{ACH})$ during each sampling event. Collection of samples in other house locations also is indicated

\begin{tabular}{|c|c|c|c|c|c|c|c|}
\hline \multirow[b]{2}{*}{ Date } & \multicolumn{2}{|c|}{ Temperature $\left({ }^{\circ} \mathrm{C}\right)$} & \multicolumn{2}{|c|}{$\begin{array}{c}\text { Relative } \\
\text { Humidity (\%) }\end{array}$} & \multirow{2}{*}{$\begin{array}{l}\text { Wind } \\
\text { Speed/ } \\
\text { Dir }^{\mathbf{a}} \\
\left(\mathrm{m} \mathrm{s}^{-1}\right)\end{array}$} & \multirow{2}{*}{$\begin{array}{c}\text { Air } \\
\text { change } \\
\text { rate } \\
\left(\mathrm{h}^{-1}\right)\end{array}$} & \multirow{2}{*}{$\begin{array}{l}\text { Other } \\
\text { Locat }^{b}\end{array}$} \\
\hline & Indoor & Outdoor & Indoor & Outdoor & & & \\
\hline 08/08/02 & 20 & 25 & 56 & 48 & $3 / \mathrm{N}$ & 0.50 & $\mathrm{C}$ \\
\hline $08 / 13 / 02$ & $21-22$ & $30-36$ & $48-55$ & $35-65$ & $2 / \mathrm{E}$ & 0.59 & \\
\hline $08 / 21 / 02^{c}$ & $21-22$ & $30-34$ & $67-70$ & $34-60$ & $\mathrm{Nm}^{\mathbf{d}}$ & 0.48 & \\
\hline $09 / 12 / 02$ & $20-21$ & $22-25$ & $48-54$ & $32-42$ & 4/SW & 0.51 & $\mathrm{C}, \mathrm{W}$ \\
\hline $10 / 24 / 02$ & 22 & 8 & $40-41$ & $62-64$ & $2 / \mathrm{E}$ & 0.26 & $\mathrm{C}$ \\
\hline $11 / 21 / 02$ & 22 & $8-9$ & 30 & $89-93$ & $1 / \mathrm{S}$ & 0.29 & $\mathrm{C}, \mathrm{W}$ \\
\hline $12 / 19 / 02^{c}$ & 22 & $7-9$ & $21-22$ & $67-69$ & $2 / \mathrm{S}$ & 0.31 & \\
\hline $01 / 17 / 03$ & $23-24$ & 13 & $22-23$ & $46-50$ & 6/NW & 0.58 & $\mathrm{C}, \mathrm{W}$ \\
\hline $03 / 12 / 03$ & 23 & $13-14$ & $22-23$ & $44-50$ & $2 / \mathrm{SW}$ & 0.31 & B \\
\hline $04 / 17 / 03$ & 28 & $10-11$ & $25-26$ & $51-55$ & $6 / E$ & 0.36 & B \\
\hline $06 / 06 / 03$ & $21-22$ & $20-22$ & $52-60$ & $47-54$ & 4/NW & 0.60 & B \\
\hline $09 / 25 / 03$ & 21 & $23-26$ & 57 & $57-63$ & $4 / \mathrm{W}$ & 0.42 & B \\
\hline
\end{tabular}

a. Direction

b. Location. $\mathrm{C}=\mathrm{Crawl}$ space; $\mathrm{W}=$ Wall cavity; $\mathrm{B}=$ Belly space

c. Aldehyde sampling only

d. $\mathrm{Nm}=$ Not measured 
Table 2. Summary of adjusted (indoor minus outdoor) concentrations and emission factors of VOCs measured over a 13 month period $(n=10$ or 11$)$. Measurement precision calculated from 10 sets of duplicate indoor samples is shown

\begin{tabular}{|c|c|c|c|c|c|}
\hline \multirow[b]{2}{*}{ Compound } & \multicolumn{2}{|c|}{ Adj Conc $\left(\mu \mathrm{g} \mathrm{m}^{-3}\right)$} & \multicolumn{2}{|c|}{ Emis Fact $\left(\mu \mathrm{g} \mathrm{m}^{-2} \mathrm{~h}^{-1}\right)$} & \multirow{2}{*}{$\begin{array}{c}\text { Precision } \\
(\%)\end{array}$} \\
\hline & Median & Range & Median & Range & \\
\hline Phenol & 14.1 & $4.5-27$ & 10.9 & $3.4-40$ & 7 \\
\hline$\alpha$-Terpineol & 1.9 & $0.8-3.9$ & 1.4 & $0.8-5.9$ & 6 \\
\hline 2-Butanone & 2.5 & $<0.5-4.5$ & 2.1 & $<0.2-6.7$ & 18 \\
\hline Formaldehyde & 84 & $25-128$ & 78 & $34-121$ & $\mathrm{Nm}^{\mathbf{a}}$ \\
\hline Acetaldehyde & 12.1 & $3.2-23$ & 10.5 & $2.4-26$ & $\mathrm{Nm}$ \\
\hline Pentanal & 12.7 & $4.6-31$ & 10.8 & $6.5-47$ & 10 \\
\hline Hexanal & 45 & $17.4-79$ & 42 & $24-118$ & 9 \\
\hline Heptanal & 4.7 & $2.1-10.5$ & 3.5 & $2.0-15.6$ & 17 \\
\hline Octanal & 8.5 & $3.6-17.4$ & 6.4 & $3.5-26$ & 14 \\
\hline Nonanal & 14.6 & $6.3-31$ & 12.8 & $6.3-45$ & 20 \\
\hline Toluene & 1.6 & $<0.5-7.0$ & 1.6 & $<0.2-6.6$ & 40 \\
\hline Styrene & 1.5 & $<0.5-3.2$ & 1.7 & $<0.4-4.8$ & 8 \\
\hline m/p-Xylene & 1.5 & $<0.5-10.2$ & 1.4 & $<0.2-15.2$ & 34 \\
\hline $1,2,4-\mathrm{TMB}^{\mathbf{b}}$ & 1.5 & $<0.5-5.7$ & 1.4 & $<0.2-8.4$ & 11 \\
\hline Naphthalene & 16.2 & $6.1-20$ & 11.1 & $6.0-28$ & 5 \\
\hline$\alpha$-Pinene & 110 & $55-190$ & 84 & $62-280$ & 9 \\
\hline 3-Carene & 8.7 & $2.9-18.2$ & 6.1 & $2.9-27$ & 5 \\
\hline Camphene & 2.0 & $0.8-3.9$ & 1.9 & $0.9-5.8$ & 6 \\
\hline d-Limonene & 8.3 & $2.8-14.3$ & 6.0 & $3.5-21$ & 6 \\
\hline p-Cymene & 1.2 & $<0.5-2.4$ & 1.0 & $<0.2-3.5$ & 7 \\
\hline n-Tridecane & 52 & $27-80$ & 42 & $29-75$ & 5 \\
\hline n-Tetradecane & 27 & $13.1-38$ & 22 & $13.9-39$ & 4 \\
\hline
\end{tabular}

a. $\mathrm{Nm}=$ Not measured

b. 1,2,4-TMB =1,2,4-Trimethylbenzene 
Table 3. Average fractional differences between living room (Lr) and master bedroom (MBr) VOC concentrations and between wall cavity, belly space, and crawl space VOC concentrations and average indoor VOC concentrations.

\begin{tabular}{|c|c|c|c|c|}
\hline \multirow[b]{2}{*}{ Compound } & \multicolumn{4}{|c|}{ Average Fractional Difference } \\
\hline & $\begin{array}{c}\text { Lr vs. } \mathrm{MBr}^{\mathrm{a}} \\
\text { Avg } \pm \text { Sdev } \\
(\mathrm{n}=7-9)\end{array}$ & $\begin{array}{l}\text { Wall vs. } \\
\text { Indoor } \\
(\mathrm{n}=1-3)\end{array}$ & $\begin{array}{l}\text { Belly vs. } \\
\text { Indoor }^{\mathbf{b}} \\
(\mathrm{n}=1-4)\end{array}$ & $\begin{array}{c}\text { Crawl vs. } \\
\text { Indoor } \\
(\mathrm{n}=2-5)\end{array}$ \\
\hline Phenol & $0.04 \pm 0.05^{\mathbf{c}}$ & -0.64 & 0.93 & -0.77 \\
\hline$\alpha$-Terpineol & $-0.02 \pm 0.08$ & -0.62 & $\mathrm{Nd}^{\mathbf{d}}$ & -0.54 \\
\hline 2-Butanone & $0.04 \pm 0.10$ & -0.47 & 3.1 & 0.13 \\
\hline Formaldehyde & $-0.05 \pm 0.20$ & 0.40 & 0.45 & -0.70 \\
\hline Acetaldehyde & $-0.24 \pm 0.58$ & 2.2 & 0.22 & -0.48 \\
\hline Pentanal & $0.01 \pm 0.08$ & -0.19 & 2.3 & -0.54 \\
\hline Hexanal & $0.01 \pm 0.05$ & -0.32 & 2.4 & -0.57 \\
\hline Heptanal & $0.03 \pm 0.13$ & -0.38 & 3.5 & -0.46 \\
\hline Octanal & $0.08 \pm 0.25$ & -0.54 & 4.1 & -0.49 \\
\hline Nonanal & $0.09 \pm 0.28$ & -0.46 & 6.5 & -0.59 \\
\hline Toluene & $0.47 \pm 0.43^{\mathbf{c}}$ & 5.6 & 2.5 & -0.32 \\
\hline Styrene & $0.11 \pm 0.07^{\mathbf{c}}$ & 0.68 & $\mathrm{Nd}$ & -0.34 \\
\hline m/p-Xylene & $0.48 \pm 0.43^{\mathrm{c}}$ & 4.8 & 9.5 & 0.20 \\
\hline $1,2,4-\mathrm{TMB}^{\mathrm{e}}$ & $0.19 \pm 0.19^{\mathbf{c}}$ & 0.05 & 7.0 & -0.32 \\
\hline Naphthalene & $0.04 \pm 0.06$ & -0.44 & 4.2 & -0.54 \\
\hline$\alpha$-Pinene & $0.02 \pm 0.08$ & -0.38 & 0.47 & -0.43 \\
\hline 3-Carene & $0.01 \pm 0.08$ & 0.32 & 0.09 & -0.35 \\
\hline Camphene & $0.02 \pm 0.09$ & -0.37 & $\mathrm{Nd}$ & -0.30 \\
\hline d-Limonene & $0.04 \pm 0.07$ & -0.33 & 0.91 & -0.38 \\
\hline p-Cymene & $0.03 \pm 0.08$ & -0.02 & $\mathrm{Nd}$ & -0.29 \\
\hline n-Tridecane & $0.04 \pm 0.07$ & -0.16 & 10.8 & -0.40 \\
\hline n-Tetradecane & $0.03 \pm 0.06$ & -0.29 & 5.2 & -0.53 \\
\hline
\end{tabular}

a. Calculated as $([\mathrm{Lr}]-[\mathrm{MBr}]) /$ average $([\mathrm{Lr}],[\mathrm{MBr}])$

b. Calculated as ([Other space]-[Indoor])/[Indoor]

c. Statistically significant difference between Lr and MBr, 2-tailed Student's t test, $\mathrm{p}>0.95$

d. $\mathrm{Nd}=$ Not detected above limit of quantitation

e. 1,2,4-TMB = 1,2,4-Trimethylbenzene 
Table 4. Emission factors of selected VOCs on adjacent sampling dates (January and March 2003) with house operating at different air change rates but nearly equivalent indoor and outdoor environmental conditions

\begin{tabular}{|c|c|c|c|}
\hline Compound & $\begin{array}{c}\text { Emission F } \\
01 / 17 / 03 \\
@ 0.58 \mathrm{~h}^{-1}\end{array}$ & $\begin{array}{c}\left(\mu \mathrm{g} \mathrm{m}^{-2} \mathrm{~h}^{-1}\right) \\
03 / 12 / 03 \\
\text { a. } 0.31 \mathrm{~h}^{-1}\end{array}$ & $\begin{array}{c}\text { Ratio Low/ } \\
\text { High air } \\
\text { change rate }\end{array}$ \\
\hline Phenol & 6.6 & 3.4 & 0.52 \\
\hline$\alpha$-Terpineol & 1.1 & 0.8 & 0.73 \\
\hline Formaldehyde & 34.9 & 33.9 & 0.97 \\
\hline Acetaldehyde & 5.6 & 2.4 & 0.43 \\
\hline Pentanal & 6.5 & 6.5 & 1.00 \\
\hline Hexanal & 24.6 & 24.3 & 0.99 \\
\hline Heptanal & 3.2 & 2.3 & 0.70 \\
\hline Octanal & 6.4 & 4.0 & 0.63 \\
\hline Nonanal & 8.9 & 6.3 & 0.70 \\
\hline Decanal & 3.2 & 1.4 & 0.42 \\
\hline Naphthalene & 8.6 & 6.0 & 0.70 \\
\hline$\alpha$-Pinene & 78.1 & 72.2 & 0.92 \\
\hline 3-Carene & 4.4 & 3.8 & 0.88 \\
\hline Camphene & 2.0 & 1.7 & 0.84 \\
\hline d-Limonene & 5.5 & 4.4 & 0.81 \\
\hline p-Cymene & 1.3 & 0.9 & 0.69 \\
\hline n-Tridecane & 38 & 29 & 0.75 \\
\hline n-Tetradecane & 18.5 & 13.9 & 0.75 \\
\hline
\end{tabular}




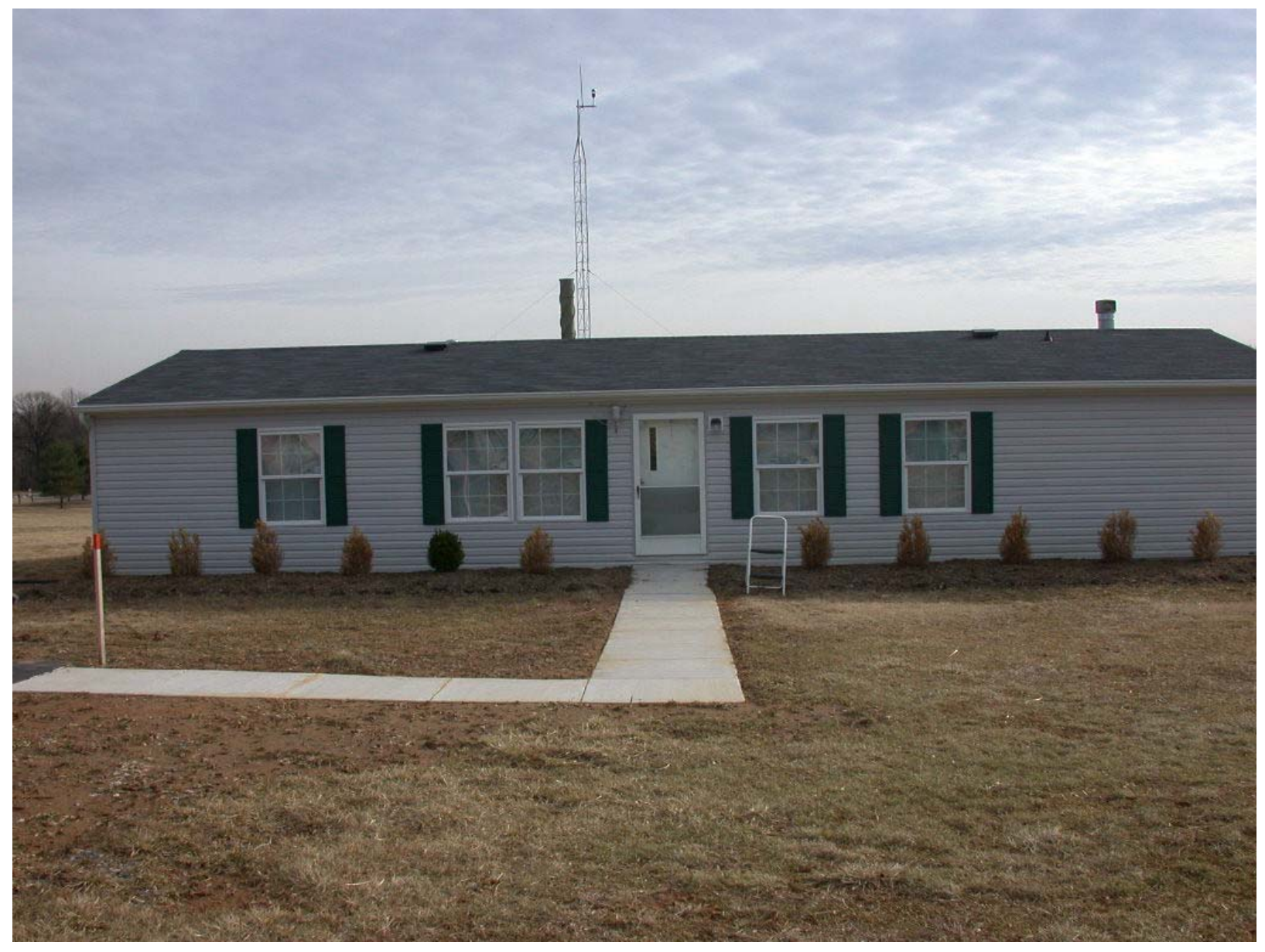

Figure 1. Manufactured study house sited on the NIST campus. 


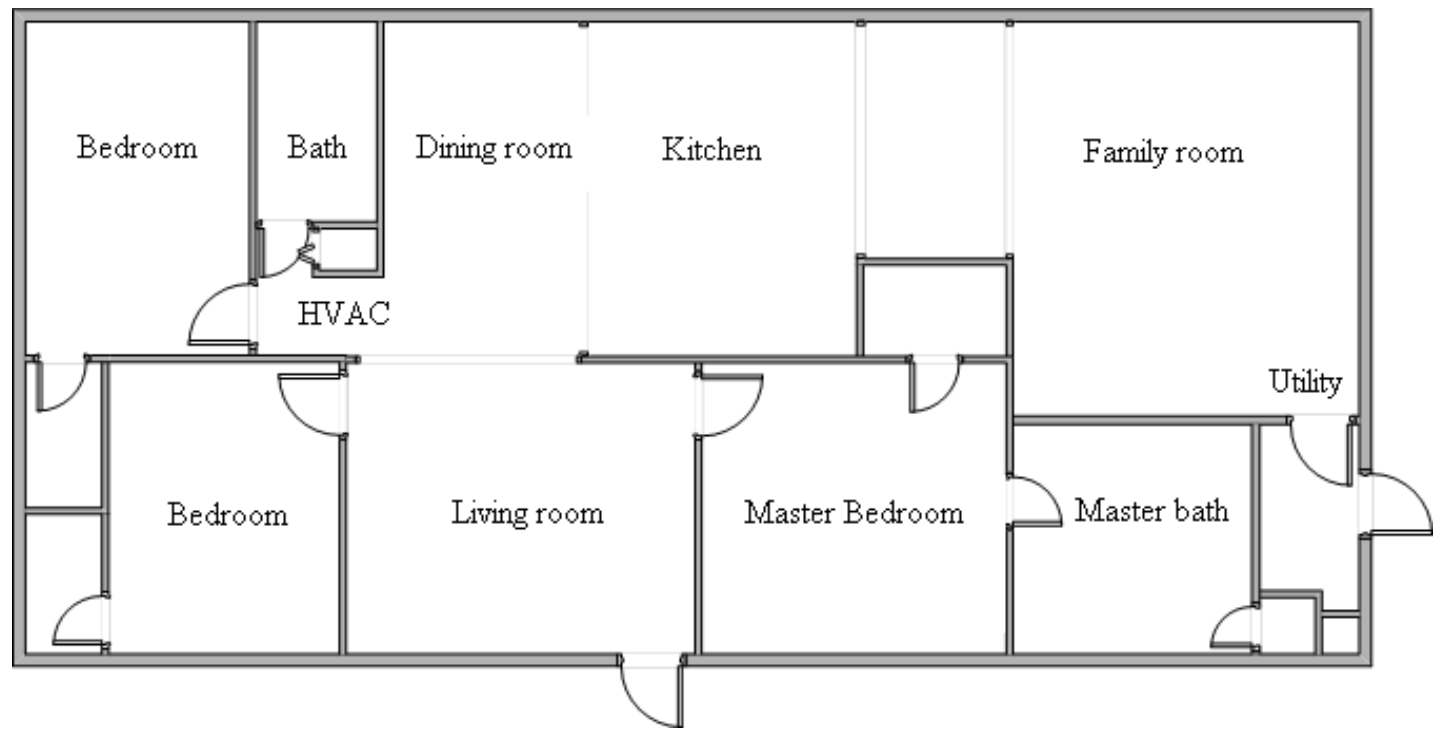

Figure 2. Schematic floor plan of manufactured study house 


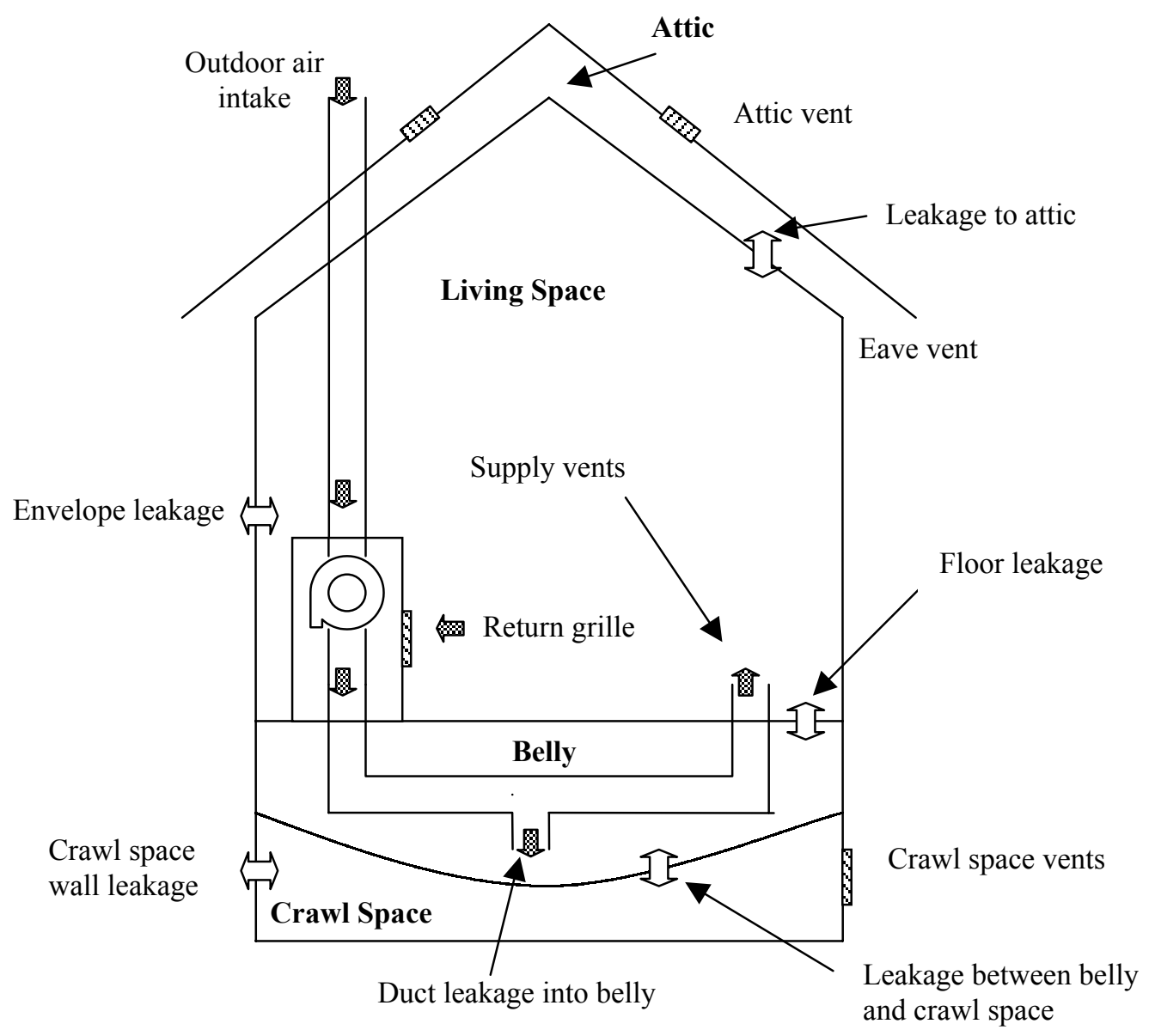

Figure 3. Schematic side elevation of manufactured study house 


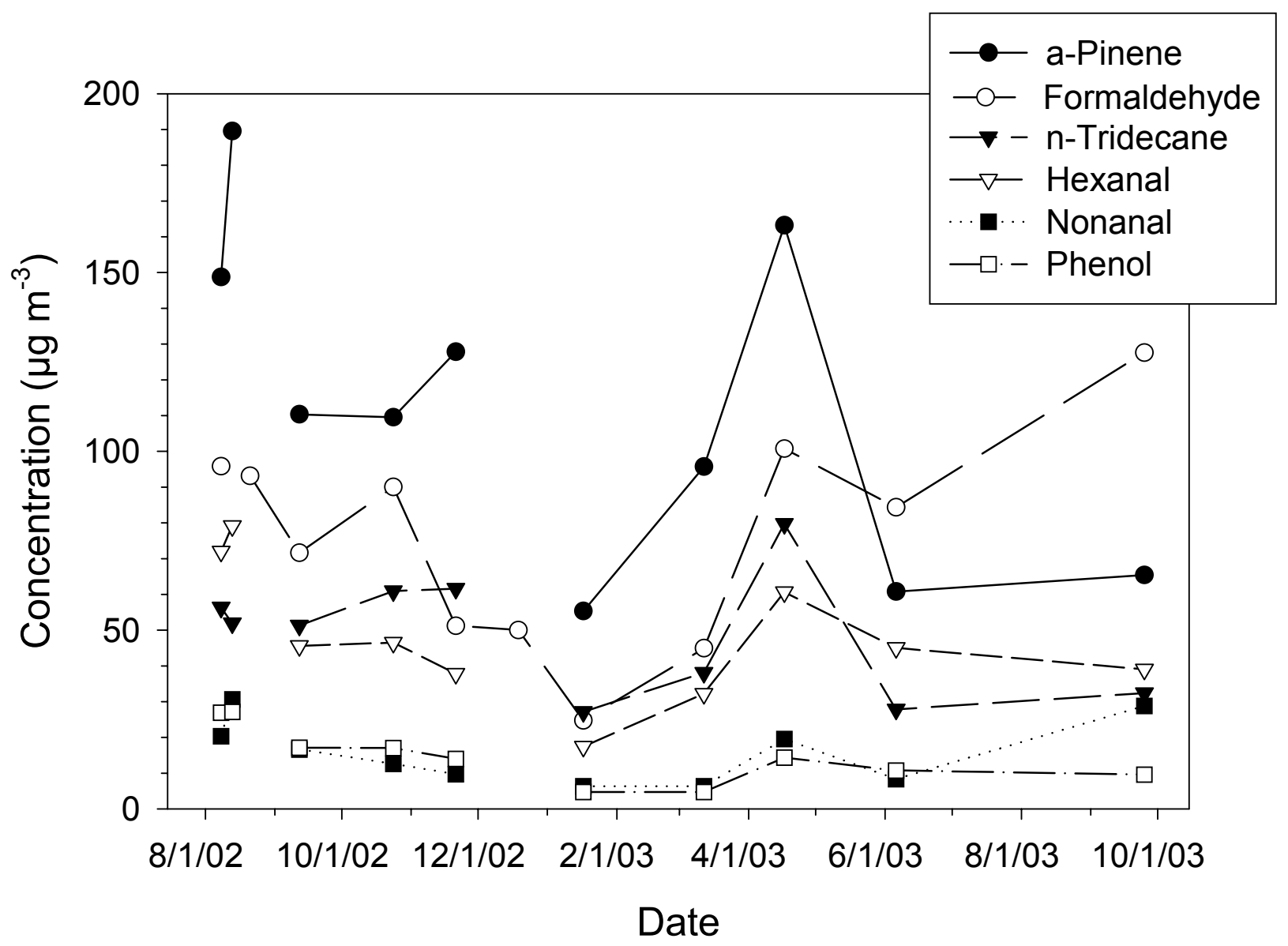

Figure 4. Indoor minus outdoor concentrations of six predominant, persistent VOCs measured from August 2002 through September 2003 


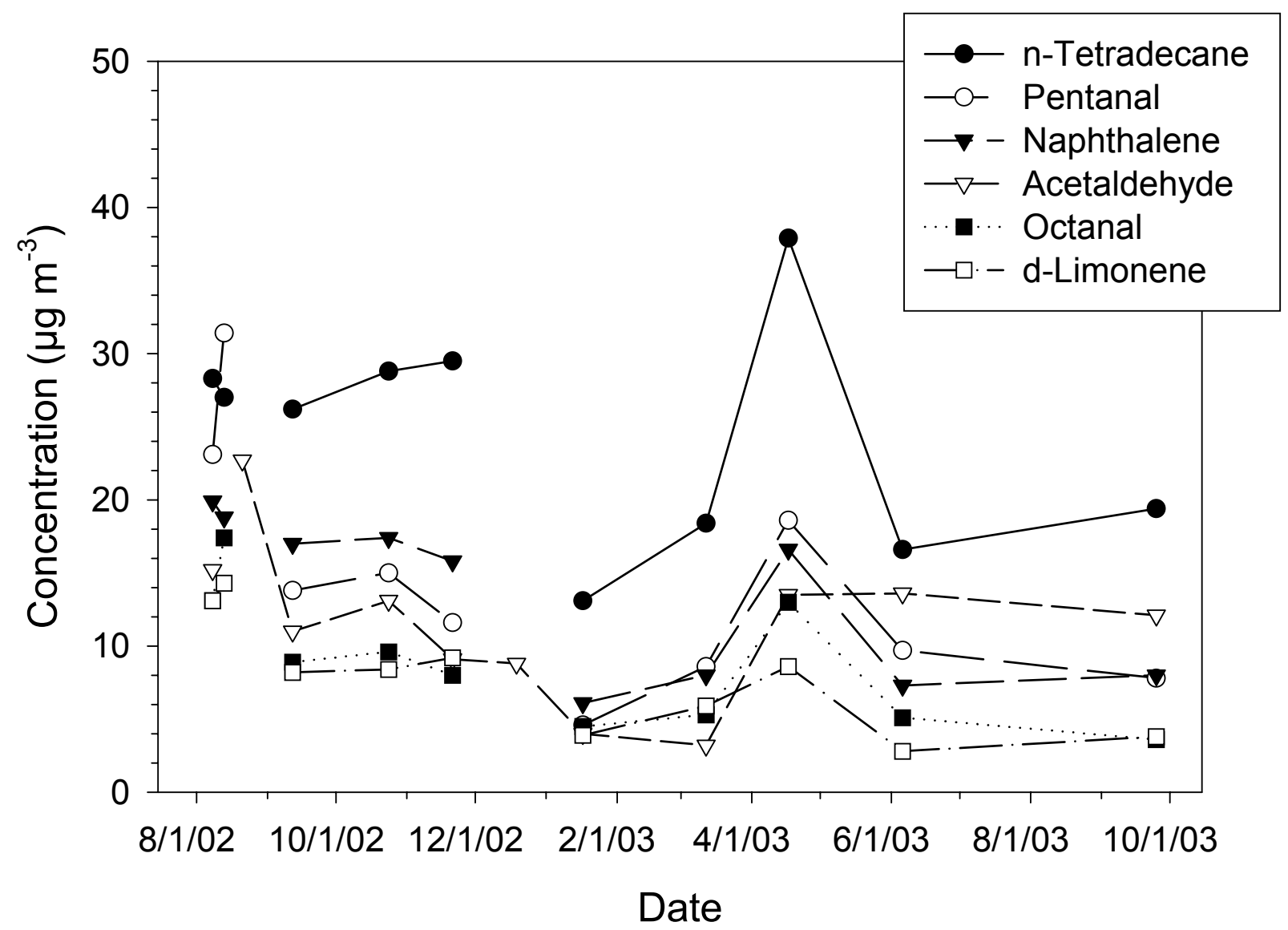

Figure 5. Indoor minus outdoor concentrations of six additional predominant, persistent VOCs measured from August 2002 through September 2003 


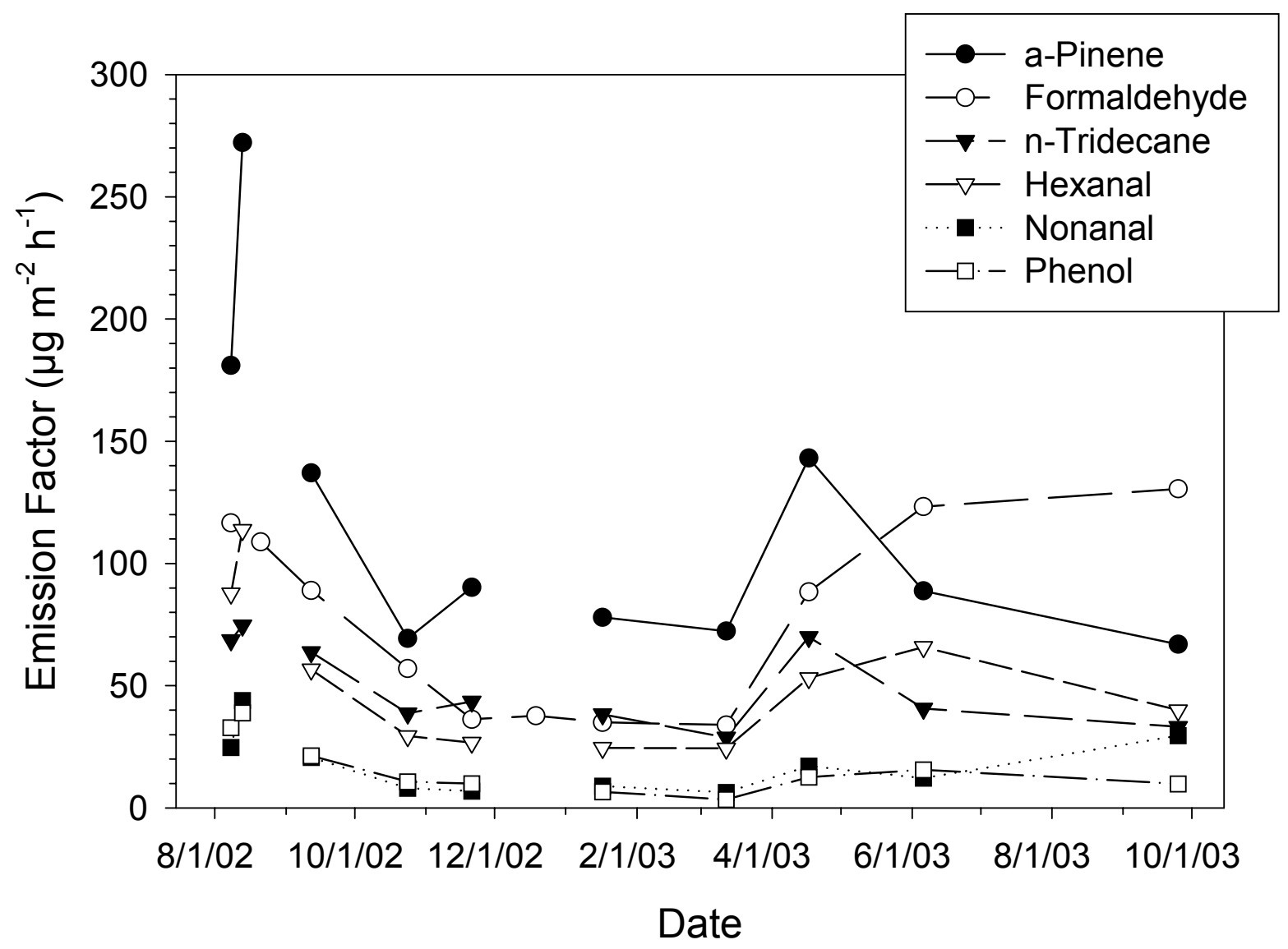

Figure 6. Emission factors of six predominant, persistent VOCs derived from measurements made from August 2002 through September 2003 


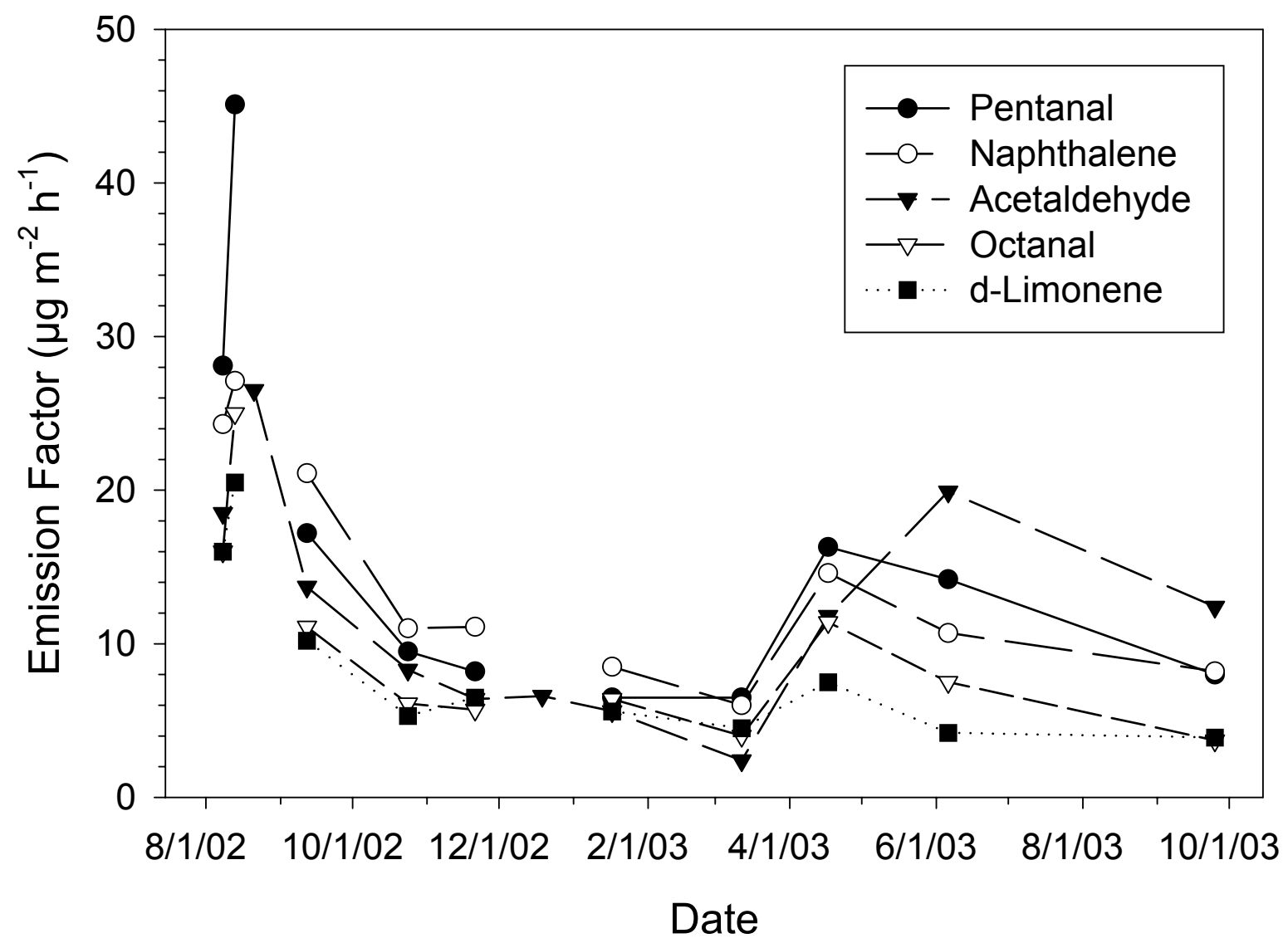

Figure 7. Emission factors of five additional predominant, persistent VOCs derived from measurements made from August 2002 through September 2003 


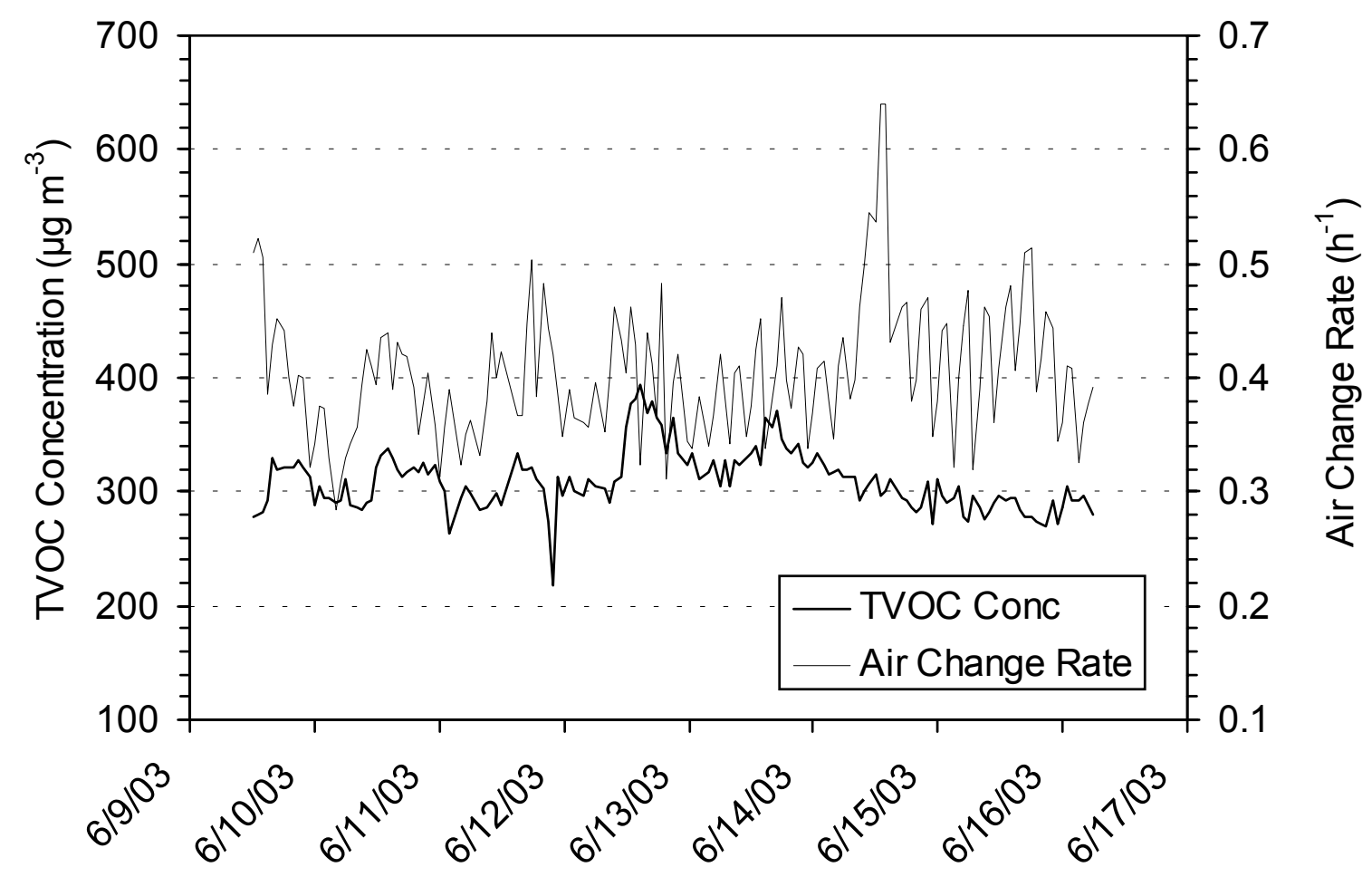

Figure 8. Semi real time TVOC concentrations and average house air change rates $(\mathrm{ACH} * 1000)$ for the week of June 9 to 16, 2003. The beginning of each day $(00: 00 \mathrm{am})$ is labeled on the date axis 


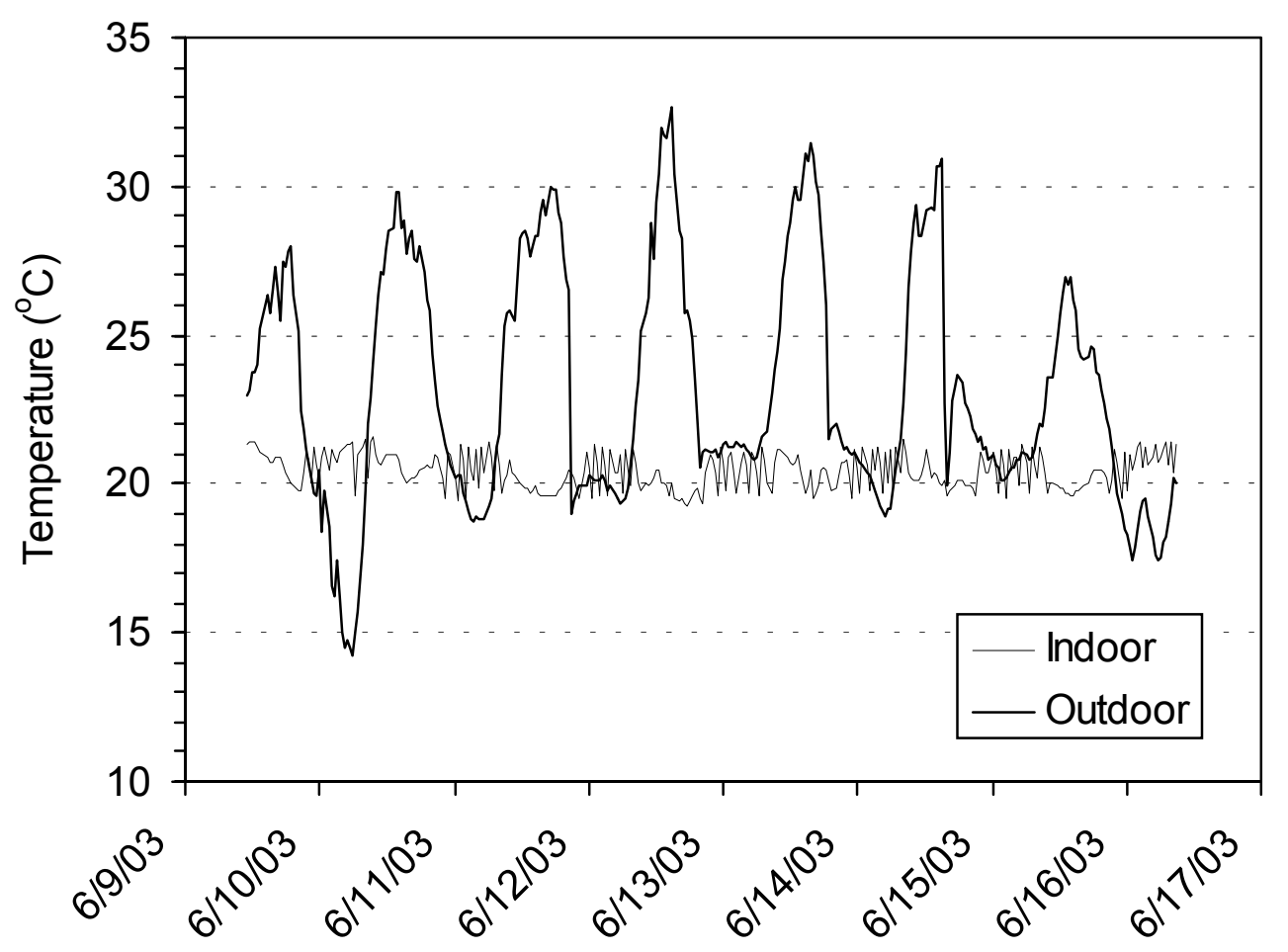

Figure 9. Indoor and outdoor temperatures for the week of June 9 to 16, 2003. The beginning of each day $(00: 00 \mathrm{am})$ is labeled on the date axis 


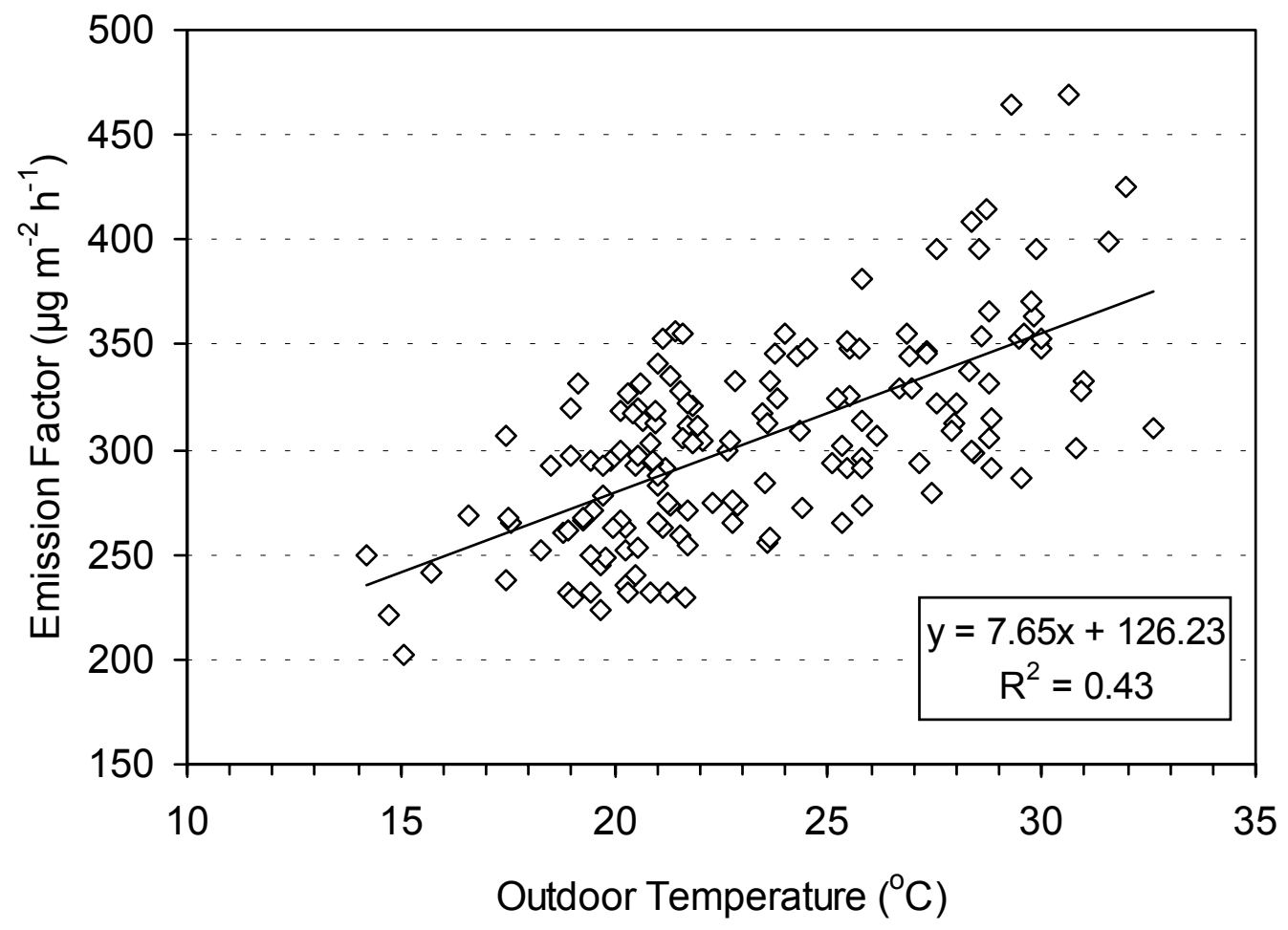

Figure 10. TVOC emission factors versus outdoor temperature for the week of June 9 to 16,2003 


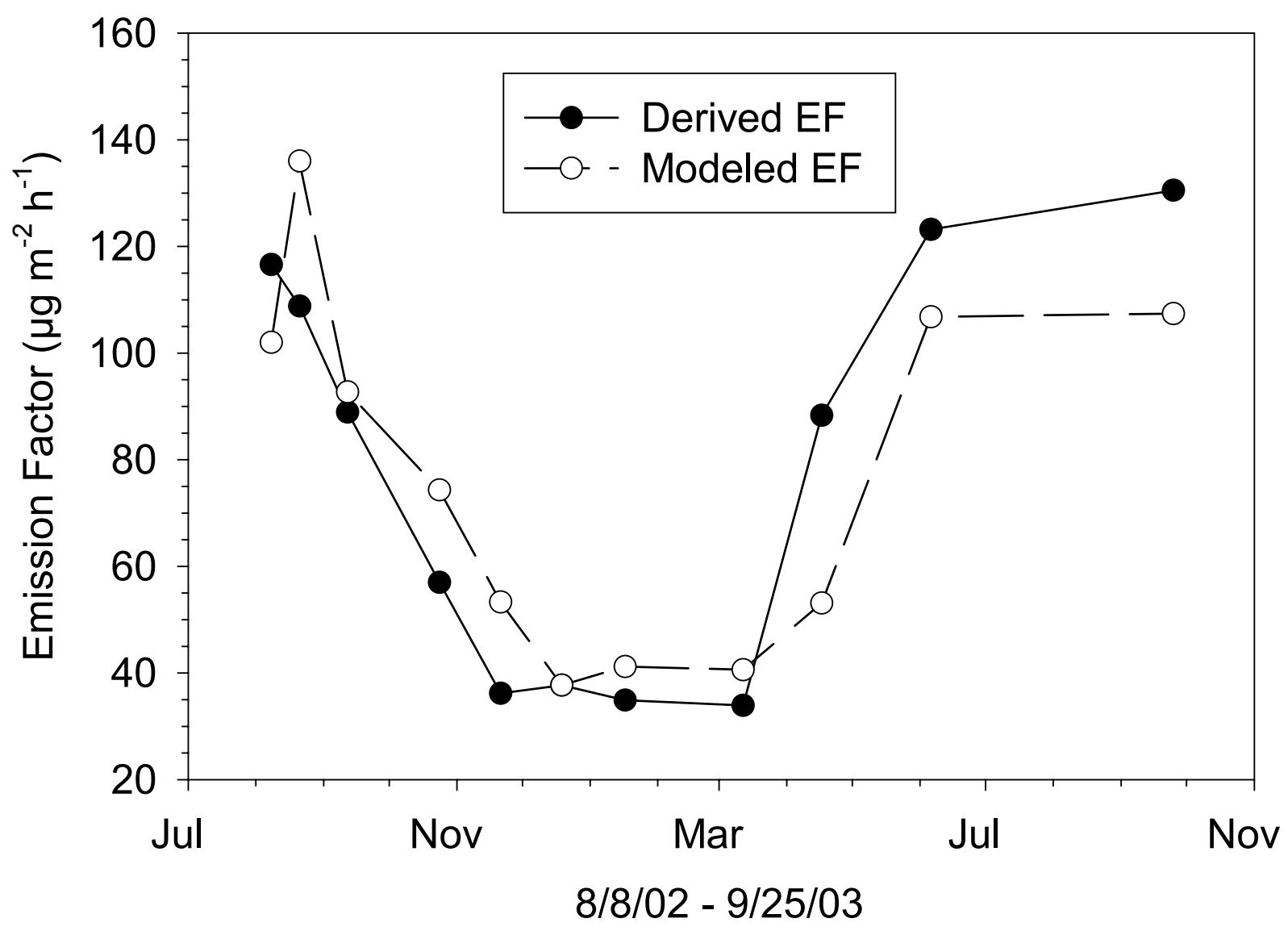

Figure 11. Derived formaldehyde emission factors for August 2002 through September 2003 and formaldehyde emission factors normalized using a model describing formaldehyde emissions from particleboard as a function of temperature, $\mathrm{RH}$ and formaldehyde air concentration. The modeled emission factor for Dec 12 was set equal to the derived emission factor for that date 